\title{
VIOLÊNCIA DE GÊNERO COMO RISCO OCUPACIONAL CONTRA ENFERMEIRAS DA ESTRATÉGIA DE SAÚDE DA FAMÍLIA DE CAMPINA GRANDE - PB ${ }^{1}$
}

\author{
Thaysa da Silva BARROS ${ }^{2}$ \\ Jank Landy Simôa ALMEIDA ${ }^{3}$ \\ Lysianne Pereira ALVES ${ }^{4}$ \\ Rejane Maria Paiva de MENEZES ${ }^{5}$ \\ Fernanda Azevedo Teixeira da ROCHA ${ }^{6}$ \\ Luzibênia Leal de OLIVEIRA ${ }^{7}$
}

${ }^{1}$ Produção científica resultante de pesquisa de projeto PIVIC - Programa Institucional de Voluntários de Iniciação Científica;

2 Graduanda em Enfermagem pela Universidade Federal de Campina Grande; Aluna PIVIC. Email: thaysasbarros@gmail.com;

${ }^{3}$ Enfermeiro; Mestre na Universidade Federal de Campina Grande; Doutorando pela Universidade Federal do Rio Grande do Norte. Email: jankalmeida@ig.com.br;

${ }^{4}$ Graduanda em enfermagem pela Universidade Federal de Campina Grande. Email: lysiannepereira@ gmail.com;

${ }^{5}$ Professora Associada III da Universidade Federal do Rio Grande do Norte - Programa de Pós-graduação. Email: rejemene@terra.com.br;

${ }^{6}$ Graduanda em enfermagem pela Universidade Federal de Campina Grande.Email: nandateixera@ hotmail.com;

${ }^{7}$ Enfermeira; Mestre na Universidade Federal de Campina Grande. Email: luzibenia @ hotmail.com.

Recebido em: 30/05/2014 - Aprovado em: 29/09/2014 - Disponibilizado em: 15/12/2014

RESUMO: Sabendo que a violência de gênero é um problema de saúde pública e que se dissipa numa constante que acaba atingindo as mulheres de forma específica e consideravelmente destrutiva, tornou-se notável a necessidade de elaborar e executar um estudo que visasse trazer conhecimentos inovadores acerca das implicações sofridas por enfermeiras da Estratégia de Saúde da Família de Campina Grande - PB, uma vez que essa classe de profissionais se mantém altamente susceptível a sofrer atos que atentem contra sua integridade física, moral, e psicossocial. Trata-se de um estudo de campo, descritivo, exploratório, de método quantiqualitativo, que visa identificar as agressões sofridas pelas enfermeiras supracitadas, os fatores motivacionais para a prática dos diversos tipos de violência sofridos e identificados através do estudo, além de especificar os agressores quanto sua ocupação e participação na rotina dessas profissionais. A pesquisa foi realizada no âmbito de 22 Unidades de Saúde da Família, do município de Campina Grande - PB, totalizando 24 enfermeiras pesquisadas. Após análise dos dados adquiridos, percebeu-se a presença persistente das próprias mulheres das comunidades no papel de agressoras, praticantes principalmente da violência moral e psicológica, realizadas preponderantemente no local de trabalho das enfermeiras.

PALAVRAS-CHAVE: Enfermagem; Violência; Estratégia de Saúde da Família; Gênero; Mulheres.

\begin{abstract}
Knowing that gender violence is a public health problem and that dissipates a constant that eventually reaches women and pretty destructive specifically, became noted the need to develop and implement a study that aims at bringing innovative knowledge about concussions suffered by nurses Strategies for Family Health Campina Grande $\mathrm{PB}$, since this class of professionals remains highly susceptible to suffer acts that threaten their physical, moral, and psychosocial. This is a field study, descriptive, exploratory, the quanti method, which aims to identify the aggression suffered by the aforementioned nurses, motivational factors for the practice of various types of violence suffered and identified by the study, in addition to specifying the aggressors as their occupation and participation in these professional routine. The research was carried out within 22 Strategies for Family Health, the city of Campina Grande PB, totaling 24 surveyed nurses. After analyzing the acquired data, we realized the persistent presence of communities of women themselves in the role of aggressor, especially practitioners of moral and psychological violence, carried out mainly in the workplace nurses.
\end{abstract}

KEYWORDS: Nursing; Violence; Health Strategies of Family; Gender; Women. 


\section{Introdução}

A persistente existência da violência no âmbito profissional é, de fato, uma grande problemática a ser enfrentada diariamente pelos profissionais de saúde, com destaque às mulheres que desempenham em maior número esse papel. Trata-se de um tema fatigante, por possuir razões multifatoriais, cuja resolução aparenta ser um objetivo distante (OLIVEIRA; ALMEIDA; MORITA, 2011).

O ambiente de trabalho pode ser danificado pela ocorrência de qualquer tipo de violência, pois de acordo com a Organização Internacional do Trabalho, a violência no local de trabalho é o ato contra um indivíduo, que seja visto como agressão, ofensa ou humilhação durante seu trabalho (VASCONCELLOS; ABREU; MAIA, 2012).

Algumas variações verificadas nos estudos sobre violência contra a mulher são mantidas pelas próprias profissionais de saúde, que enfrentam diariamente a responsabilidade de lidar com as vítimas que solicitam assistência, e que por se fazerem em maior número entre profissionais de enfermagem, sentem-se tocadas pelo drama ainda vivenciado por muitas delas (OLIVEIRA; D'OLIVEIRA, 2008).

Estudos anteriores ainda relembram que a violência contra a mulher ou violência de gênero está delineada perante as desigualdades ainda fortemente existentes entre soberania de homens e mulheres, ascensão de ambos os sexos nas profissões, e em questões sociais, o que permite que ainda seja árdua a tarefa de extingui-la (OLIVEIRA; D'OLIVEIRA, 2008).

A violência em questão gera sentimentos de impotência, restrição profissional, insucessos e culpabilidade das enfermeiras sobre si mesmas e sobre a agressão sofrida, porém alguns estudiosos ainda persistem com a ideia de que o ato de violência não tem conexão alguma com estatísticas que mostrem prevalência quanto ao sexo da vítima (VASCONCELLOS; ABREU; MAIA, 2012).

Diante do fato de que a violência de gênero, principalmente no tocante às profissionais de saúde, ser pouco estudada mundialmente, é indispensável uma iniciativa por buscas de respostas mais convincentes e que de alguma forma direcione a efetuação de ações contra tal fato (OLIVEIRA; D'OLIVEIRA, 2008).

Deve-se considerar que uma justificativa bastante utilizada é que a ocorrência de violência psicológica entre enfermeiras se deve à inferiorização da profissão diante dos preconceitos da sociedade, e pela predominância do sexo feminino entre essa classe de profissionais (BARBOSA et al, 2011).

Assim, e tomando por base o denotado cenário de violência de gênero exposto $\mathrm{o}$ 
presente estudo objetivou investigar a violência de gênero praticada contra enfermeiras na Estratégia de Saúde da Família, do município de Campina Grande PB, caracterizando os episódios de violência quanto ao local, modelos, e meios utilizados para tal, bem como evidenciar os motivos da prática dos diversos tipos de violência, e classificando as agressoras quando sua função na sociedade e hábitos profissionais das enfermeiras.

\section{Metodologia}

Trata-se de um estudo aplicado, de campo, descritivo, exploratório, de método quantiqualitativo.

A pesquisa foi realizado no domínio de 22 Unidades de Saúde da Família do município de Campina Grande - PB, com participação de 24 enfermeiras pesquisadas, respeitando a proposta de executar a coleta de dados e análise de pesquisa durante o período de 12 meses.

A amostra considerada apta para exame foi composta exclusivamente por mulheres, que são enfermeiras, que aceitaram colaborar com a pesquisa e exercem a profissão em qualquer das Unidades de Saúde da Família de Campina Grande-PB.

Para a coleta de dados primários, foi utilizado um questionário auto-explicativo, com questões pertinentes à problemática proposta, e aplicado de forma individual com cada enfermeira respondente, preservando assim a privacidade e qualquer tipo de constrangimento durante o preenchimento do mesmo.

O estudo respeitou os aspectos éticos recomendados pela Resolução 466/12 do Conselho Nacional de Saúde, e a partir do Termo de Consentimento Livre e Esclarecido concedeu sigilo, privacidade e segurança acerca da pesquisa, para as enfermeiras pesquisadas.

\section{Resultados e Discussão}

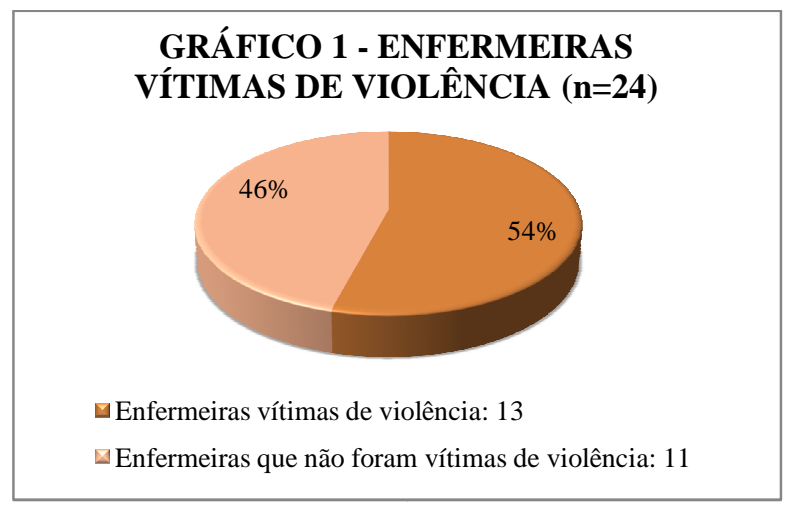

Mais da metade das enfermeiras alegaram não ter sofrido qualquer tipo de violência em sua prática profissional em Unidades Básicas de Saúde, seja pelo período prolongado de atividades em determinada Unidade, pela boa receptividade dos usuários da área, ou mesmo pela compatibilidade amigável entre o serviço prestado e as necessidades que a comunidade apresente. As enfermeiras vitimadas e representadas por $46 \%$, permitem o ingresso a tantas outras questões que compreendem a busca ativa por maiores esclarecimentos a respeito da violência de gênero contra enfermeiras. 
É de bom tom uma qualificação da relação entre profissional de enfermagem da Unidade Básica de Saúde da área e a comunidade, recapitulada por Oliveira, Almeida e Morita (2011), posto que diante de determinadas áreas de risco, a probabilidade de execução da violência torna-se maior, pois o conhecimento e captação dos habitantes dessas áreas por vezes são precários, mantendo a equipe de saúde desprovida de conhecimento sobre toda a comunidade e se a receptividade é eficaz.

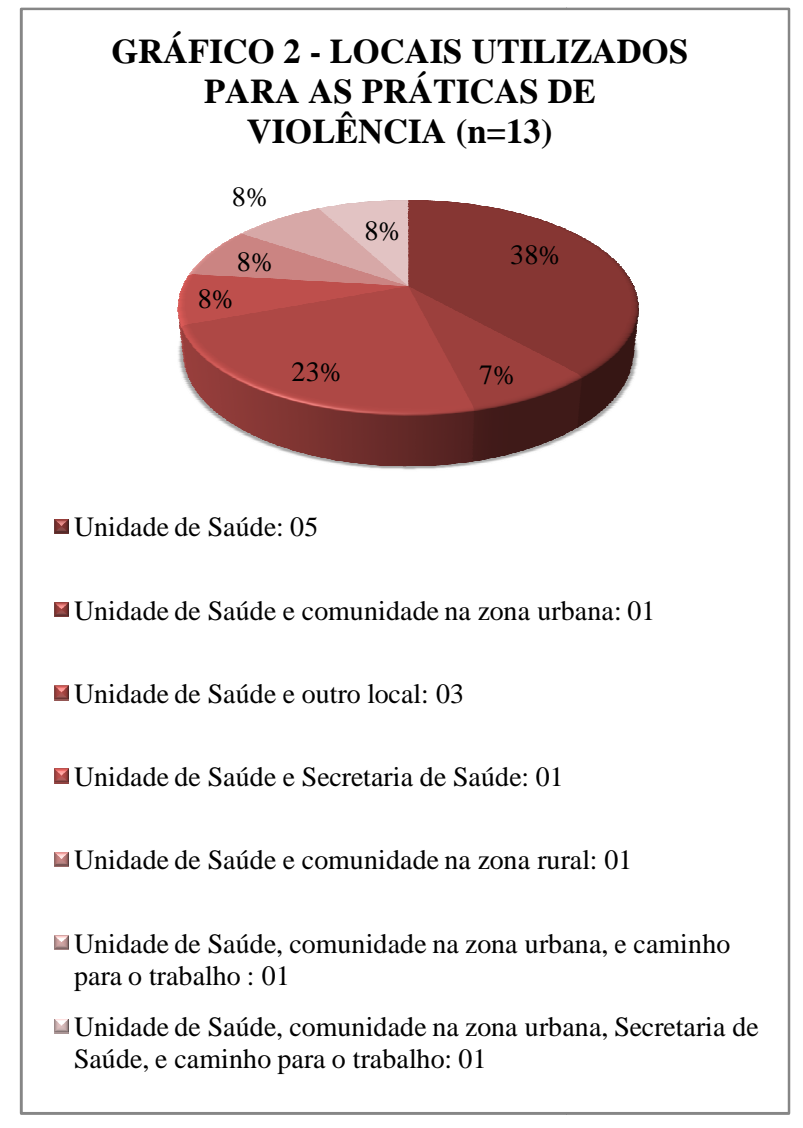

Diferentes locais foram referidos na pesquisa, entre eles, uma comunidade indígena e um hospital. Acredita-se que a violência em comunidade indígena se deva pelo despreparo do próprio profissional acerca dos direitos sociais dos habitantes das existentes aldeias, bem como sobre a cultura a qual eles pertencem, regras de convivência e rituais. É necessário lembrar que comunidades como esta que permaneçam conservadoras, podem estabelecer certo bloqueio aos cuidados prestados pela profissional de enfermagem, o que se agrava no caso da falta de maturidade profissional.

Este argumento pode ser fortificado perante o estudo de Martinelli et al (2012), que demonstra que o enfermeiro direcionado à comunidade indígena não se mantém preparado quanto às capacitações necessárias, o devido esclarecimento acerca da cultura da comunidade a ser assistida, e as práticas medicinais próprias daquele povo.

Barbosa et al (2011) descrevem em estudo que as profissionais de saúde não estão salvas de sofrerem violência. Essas autoras compararam os riscos dessas profissionais em rotina hospitalar e o dia-a-dia das mulheres em geral, e constataram que as enfermeiras encaram com maior frequência o risco de serem agredidas, do que a população representada pelas mulheres. Esse fenômeno epidêmico ocorre devido ao contato repetitivo das enfermeiras com pacientes, parentes de pacientes, chefes e colegas de trabalhos, que praticam continuamente os tipos de violência existentes.

Os demais locais ditos como ambientes para a prática da violência 
permanecem em minoria, porém não perdem importância de debate, já que a identificação dos agressores é imprescindível para estudos e divulgações acerca da disseminação do hábito destrutivo da violência, e sobre ações determinantes para a proteção das profissionais de enfermagem.

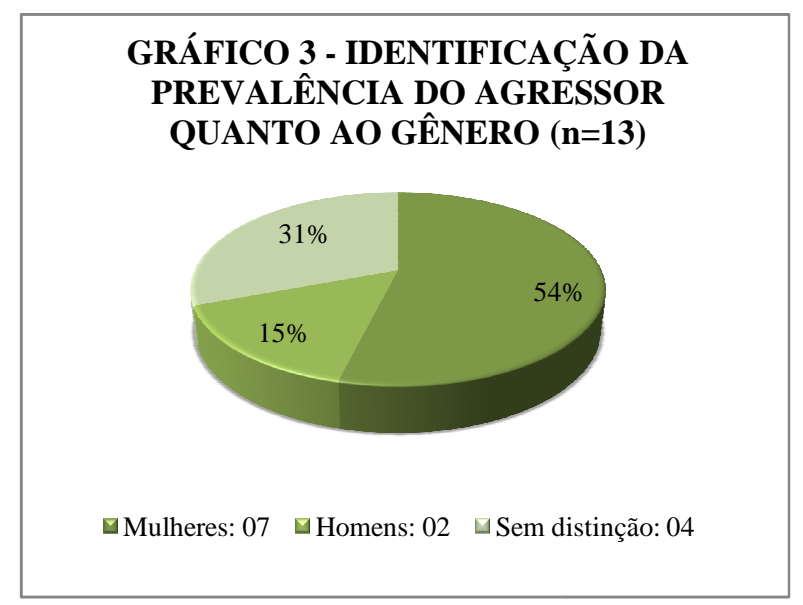

Os resultados evidenciam outra faceta da violência, onde a realidade se inverte e, neste caso, as enfermeiras das Unidades Básicas de Saúde, são vitimadas pelas próprias mulheres.

Verifica-se uma instabilidade na segurança das profissionais de enfermagem no âmbito dos seus locais de trabalho. Por conseguinte Contrera-Moreno e ContreraMoreno (2004) discorrem sobre os fatores atrelados aos riscos que essas profissionais correm, e relatam de modo substancial as justificativas pertinentes ao tema. Para as autoras, o contato direto e pouco compreensivo por parte das profissionais, por vezes, é digno de culpabilidade pelo ato violento aplicado.
As autoras supracitadas acentuam que a própria área de atuação das enfermeiras pode ser encarada como risco. Caso a população tenha acesso a drogas e porte de armas, a receptividade da enfermeira pela comunidade pode ser consideravelmente abalada. Atendimento pouco humanizado ou precário, existência de pacientes de saúde mental na área, e idosos insatisfeitos podem romper a linha da serenidade, despontando revolta populacional e resolução por meio da violência.

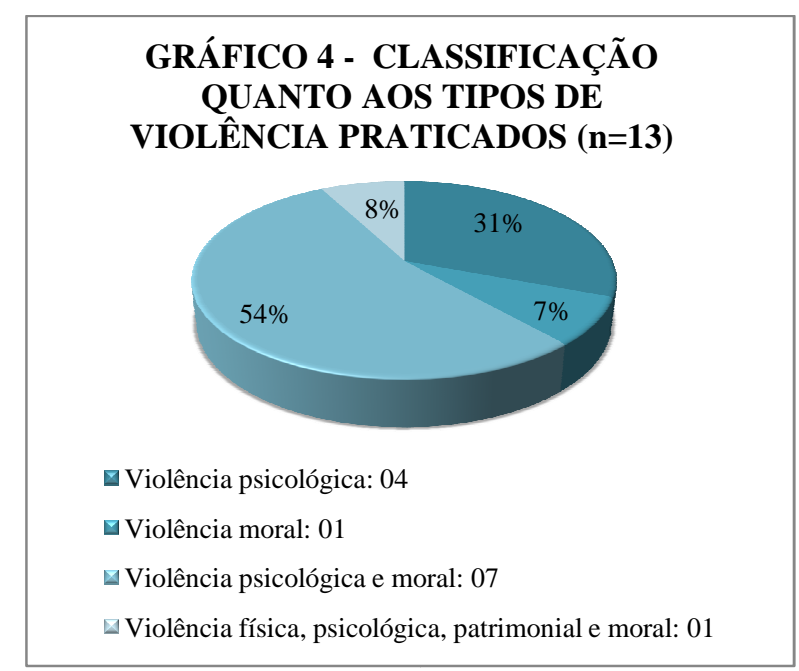

O gráfico 4 demonstra que agressão psicológica e moral na maioria das pesquisadas servem de companhia uma para a outra, enquanto que a minoria declara a prática isolada da violência moral. Acredita-se que a união desses dois tipos de violência provenha justamente da associação entre suas consequências, posto que a psicológica causa danos tanto a identidade da enfermeira, quanto à sua auto-estima, que pode ser sequência da agressão moral, finalizada em momentos de embaraço para a vítima. 
Pode-se justificar esse ponto de vista a partir da ideia defendida por Barbosa et al (2011), em que os mesmos relembram que a violência psicológica é vista como uma síndrome psicossocial, por atingir determinado indivíduo, causando reações indesejáveis em seu âmbito social e profissional que alcançam nível coletivo; e multidimensional por resultar em sintomas físicos e psíquicos de restauração lenta.

A violência moral é posta por Bobroff e Martins (2013) como qualquer ato que leve a vítima passar por degradação, aflição ou mal-estar diante de certas situações. Acreditase que mesmo com a forte existência da violência física, a psicológica é menos notificada de forma que certas estatísticas tornam-se maquiadas dentro dos ambientes de trabalho.

Barbosa et al (2011) afirmam que as mulheres estão mais predispostas a sofrer violência psicológica por serem mais frágeis e constituírem um número maior entre os profissionais de saúde, mostrando que a revelação desse tipo de violência implicaria no risco das boas atividades do trabalho da equipe de saúde seja em instituição pública ou privada.

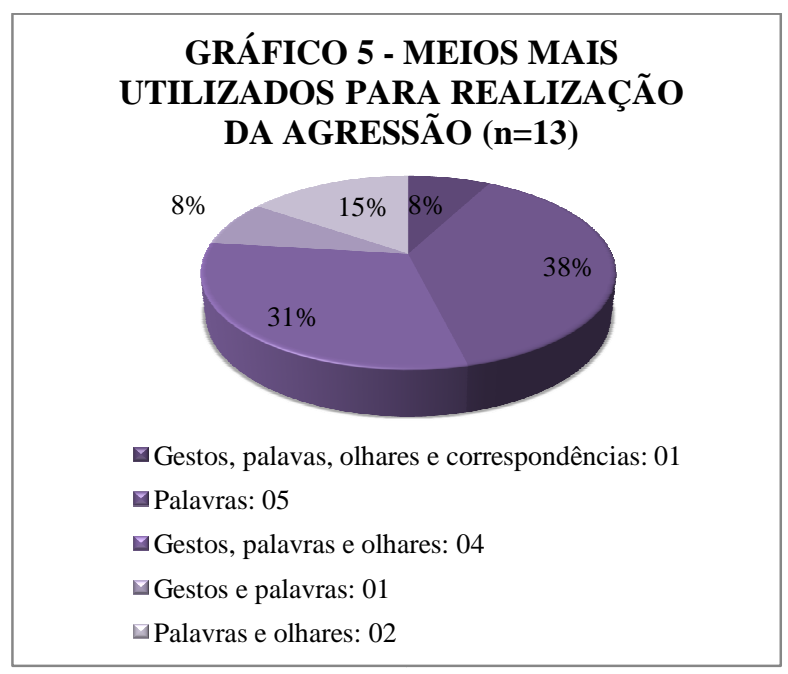

Ainda que a violência física aparente ser mais persuasiva e prejudicial, percebe-se de acordo com o gráfico que a violência verbal deterioriza mais velozmente o estado psicológico da vítima quando comparada a agressão corporal. Velloso, Araújo e Alves (2011) relembram que o comportamento de quem sofre a agressão psicológica, representada com predominância neste estudo pelas palavras, gestos e olhares, modifica-se como um ato de sobrevivência com o objetivo de sanar a freqüência ou intensidade das agressões.

Os atos violentos descritos no gráfico e representados pelas palavras, gestos e olhares ofensivos foram colocados por Barbosa et al (2011) como atos que deteriorizam o prestígio das enfermeiras e inferiorizam o brilho de suas identidades. As atitudes mais comuns e intimidantes encontradas são interrupção do discurso da profissional, utilização de palavras maldosas com intenção de silenciar a enfermeira, ignorar a presença da mesma ou até comentar 
a vida privada, expondo-a de maneira constrangedora como forma de censura. Os autores ainda relatam que quanto mais jovem e inexperiente for a profissional, mais susceptível estará à sofrer atos de violência em ambiente de trabalho, bem como menor a probabilidade de se posicionar diante das atribulações e contorná-las de forma eficaz e segura.

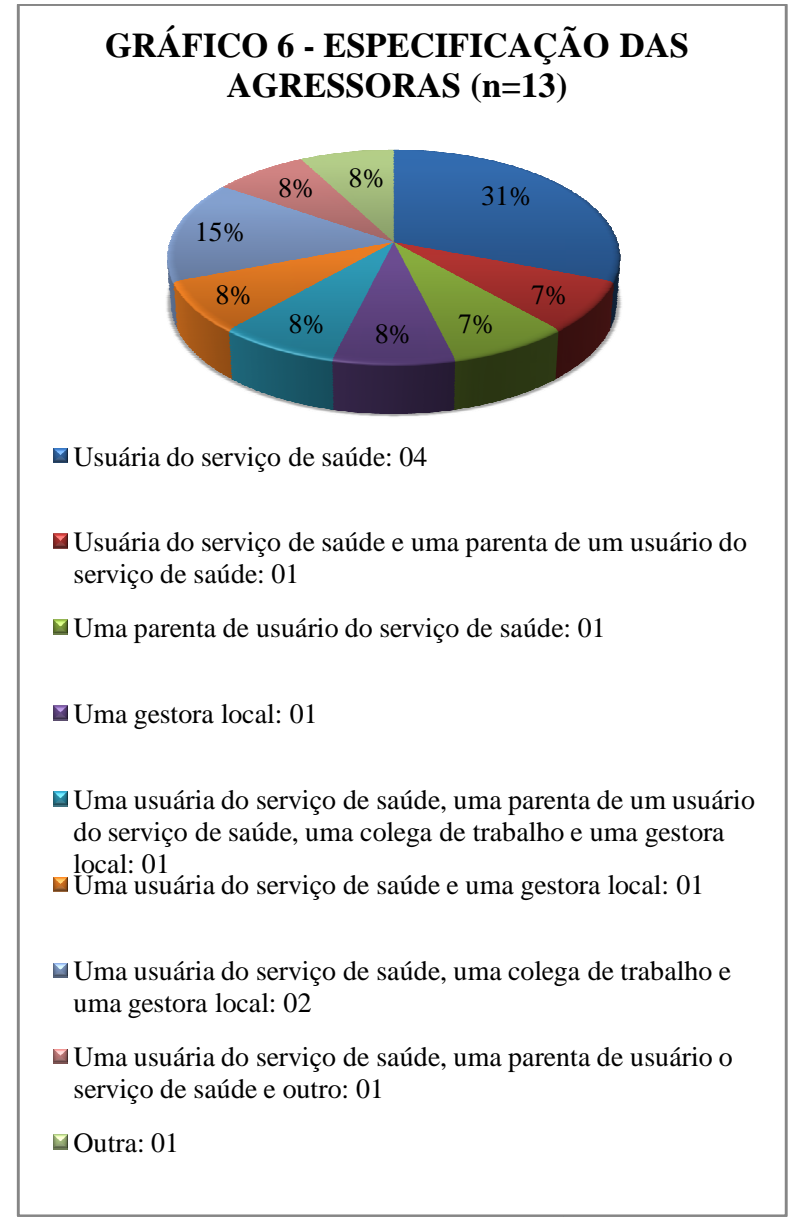

O gráfico 6 evidencia que $31 \%$ das principais agressões que ocorrem contra enfermeiras das Unidades de Saúde da Família, provém de usuárias do serviço de saúde. As demais agressões são quantificadas com cerca de $8 \%$ cada, estabelecendo-se uma agressão para um total de 13 entrevistas válidas.

A presença de diferentes agressores sugere a violência de gênero, e na enfermagem que é uma profissão predominantemente feminina, as enfermeiras sofrem as conseqüências da subalternidade vivenciada pelas mulheres desde os primórdios. Nesse sentido, é necessária uma nova postura profissional, alicerçada na reflexão sobre as relações sociais de gênero (BARBOSA et al, 2011).

Segundo Vasconcellos, Abreu e Maia (2012), a sobrecarga de trabalho, o estresse e a diminuição da qualidade da assistência ao paciente, contribuem com a insatisfação por parte dos familiares e pacientes e gerando assim as agressões.

A interferência da violência no processo de trabalho é a ponta de um problema muito mais amplo, que deve ser objeto de políticas específicas pelo poder público visando à melhoria de condições de vida da população, a partir da melhor compreensão da interdisciplinaridade desse processo (VELLOSO; ARAÚJO; ALVES, 2011).

\section{Considerações}

O estudo aprofundou o conhecimento das justificativas paras a para ocorrência da violência de gênero contra as enfermeiras e como esses atos de violência impactaram no 
rendimento profissional, na relação profissional-usuário, e quais os (as) agressores que atuaram na efetivação da violência. Percebeu-se que diferentemente do que ocorre na sociedade em geral, o homem teve participação minoritária na realização da violência contra as enfermeiras, seja pela ausência de diálogo, pela forma errônea de encarar o trabalho realizado por tais profissionais ou mesmo pela área de sua comunidade, mas principalmente, por não ter um contato consideravelmente equivalente ao que as mulheres das comunidades têm com as enfermeiras.

Considerando que a própria mulher, usuária de Unidade de Saúde, se policia mais a ponto de buscar assistência nesse serviço, é possível determinar fatores que a induzem a praticar violência, tais como área em que reside, precariedade do serviço, baixa resolutividade de suas queixas, bem como a própria impossibilidade de atendimento visto por muitas como urgencial, mas que tendem a enfrentar a demanda existente sobre responsabilidade da enfermeira.

Percebeu-se que a violência não se limita à estrutura do ambiente de trabalho dessas enfermeiras, pois tanto as redondezas quanto os demais serviços que pedem a presença de outros níveis hierárquicos de profissionais, resguardam situações bastante oportunas para aplicação dos atos de violência.
Existe potencialmente a necessidade da procura pelo saber da violência contra as profissionais em questão, pois determinando fatores e locais de risco, identificando a população e por meio de estudos notificar essas agressões, espera-se que se diluam as ocorrências de atos violentos contra a categoria de enfermeiras, tornando viável a elaboração de intervenções proporcionais aos traumas existentes, e disseminação das mesmas às outras classes profissionais vitimadas pela mesma problemática.

\section{Referências}

BARBOSA, Rute; LABROCINI, Liliana Maria; SARQUIS, Leila Maria Mansano; MANTOVANI, Maria de Fátima. Violência psicóloga na prática profissional da enfermeira. Rev.Esc. Enferm. USP, 2011.

BOBROFF, Maria Cristina Cescatto; MARTINS, Júlia Trevisan. Assédio moral, ética e sofrimento no trabalho. Rev. Bioét., Brasília, v. 21, n. 2, Aug. 2013.

CONTRERA-MORENO, Luciana; CONTRERA-MORENO, Maria Inês.

Violência no trabalho em enfermagem: um novo risco ocupacional. Rev. bras. enferm., Brasília , v. 57, n. 6, Dec. 2004.

MARINELLI, Natália Pereira, et al. Assistência à população indígena: dificuldades encontradas por enfermeiros. 
Revista Univap. São José dos Campos-SP, v.

18, n. 32, dez.2012.

OLIVEIRA, Ane R; D’OLIVEIRA, Ana

Flávia P L. Violência de gênero contra

trabalhadoras de enfermagem em hospital

geral de São Paulo. Rev. Saúde Pública,

2008; 42 (5):868-76.

OLIVEIRA, Cristiano Claudino; ALMEIDA, Margareth Aparecida Santini de; MORITA,

Ione. Violência e saúde: concepções de profissionais de uma Unidade Básica de Saúde. Rev. bras. educ. med., Rio de Janeiro, v. 35, n. 3, Sept. 2011 .
VASCONCELLOS, Ilmeire Ramos

Rosembach de; ABREU, Ângela Maria

Mendes; MAIA, Eveline de Lima. Violência ocupacional sofrida pelos profissionais de enfermagem do serviço de pronto atendimento hospitalar. Rev. Gaúcha Enferm., Porto Alegre, v. 33, n. 2, June 2012 .

VELLOSO, Isabela Silva Câncio; ARAUJO, Meiriele Tavares; ALVES, Marília.

Trabalhadores de uma Unidade Básica de Saúde na interface com a violência. Acta paul. enferm., São Paulo, v. 24, n. 4, 2011 